\title{
Investigating the Technical and Social Affordances of Moodle Usage among Senior High Schools Students in the Greater Accra Region
}

\author{
Comfort Amoako-Attah1, Clarke Ebow Yalley2* (i) \\ ${ }^{1}$ Department of Mathematics, Science and ICT, College of Distance Education, University of Cape Coast, Cape Coast, Ghana \\ ${ }^{2}$ Department of Social Studies Education, University of Education, Winneba, Ghana

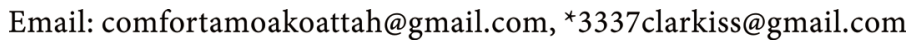

How to cite this paper: Amoako-Attah, C., \& Yalley, C. E. (2021). Investigating the Technical and Social Affordances of Moodle Usage among Senior High Schools Students in the Greater Accra Region. Creative Education, 12, 1629-1642.

https://doi.org/10.4236/ce.2021.127124

Received: June 22, 2021

Accepted: July 23, 2021

Published: July 26, 2021

Copyright $\odot 2021$ by author(s) and Scientific Research Publishing Inc. This work is licensed under the Creative Commons Attribution International License (CC BY 4.0).

http://creativecommons.org/licenses/by/4.0/

(c) (i) Open Access

\begin{abstract}
The justification for conducting this study was to investigate the technical and social affordances of Moodle usage among Senior High School students in the Greater Accra region of Ghana. The positivist research paradigm and quasi-experimental research design was adopted for the study. The purposive sampling procedure was used to sample 301 respondents for the study. The Cronbach alpha value of 0.83 was obtained on the structured questionnaire. The findings of the study revealed that students were able to submit project works on time, viewed their grades and received prompt feedback. Also, students were able to connect with teachers and other students, shared ideas or communicate within the Moodle platform effectively. It is recommended that the government, National Council for Curriculum and Assessment (NaCCA), educational policymakers provide workshops on Moodle usage for students to acquire the needed technical skills in operating the Moodle platform. Moodle manuals should be designed for students to serve as a guide to aid students to navigate smoothly when using the Moodle platform.
\end{abstract}

\section{Keywords}

Moodle, Technical Affordance, Social Affordance, Cognitive Information

Processing, Socio-Cultural Model of Learning

\section{Introduction}

Technology, since its inception, has been rapidly increasing and changing. It has brought a lot of advancements in the various sectors of many countries. For in- 
stance, there have been immense advancements in sectors like education, health, journalism, agriculture, government and sports (Chindo, Bala, Tijani, Waziri, \& Maji, 2015). The most common application of these technological advancements is the fast and easy way of sharing and accessing information. The education sector has taken advantage of this improvement in technology and has made access to quality educational information extended beyond the four walls of the classroom.

Education has gained numerous benefits in terms of improvement on how information is shared and accessed. It is now optional to sit in the traditional classroom to learn; development of high-tech pedagogies; and exploitation of modern learning strategies are the popular benefits education has gained from technology (Crawford, 2000). The role of a classroom teacher has changed from teaching all subjects to supervising or guiding students. This is because students can now learn on their own and access learning materials from varied educational technological tools (Putnam, 2006). Students predominately refer to the continuous use of digital technology and the internet tailored towards teaching and learning within the educational institutions as eLearning.

Moodle is an acronym of Modular Object-Oriented Dynamic Learning Environment. It is an online Learning Management System that allows teachers to add educational information and other contents for students to access them. Moodle is an open-source application and hence its access and usage are free. It has tools which support collaborative interaction among students and the provision of online inquiry and discovery learning (Brandl, 2005). Obviously, teachers and students will take advantage of the free access to the Moodle platform to support their classroom activities. Moodle has been globally accepted and most used online learning management system by students and teachers. On the average, students access this platform 49 times per month (Costa, Alvelos, \& Teixeira, 2012). The collaborative tools of Moodle help students to work together as a group, evaluate their performance, create email accounts, chat, access grades, and view learning progress (Costa, Alvelos, \& Teixeira, 2012). Moreover, students visit the Moodle platform to download learning materials, present assignments, take tests, communicate with teachers and peers, and sometimes access news items.

Like any other learning management systems, Moodle has its perceived capabilities and limitations. These two elements (capabilities and limitations) influence the use of the technology. One of the concepts under capabilities and limitations is the technology affordance. Affordance involves the perception of objects and the action they produce (Treem \& Leonardi, 2013). For instance, Moodle has objects like the log-in, profile, dashboard, notification, my courses, download, upload, blogging, quizzes, assignment, and so on (Jan, Amin, \& Mattoo, 2018). These objects have perceived affordances. For example, download affords transferring files from the platform to your computer or mobile device while upload affords transferring files from your computer to the Moodle platform. Advanced knowledge on the Moodle affordances influences the use of the platform. 
Moodle affordances present themselves in various types. For instance, Said and Bin (2014) came out with three types of Moodle affordances. They are technical, social and pedagogical. The technical affordance involves the knowledge in the use of the Moodle technology like how to upload assignments and download materials. The social affordance deals with the knowledge on how to interact on the platform, while the pedagogical affordance looks at the various skills involved in lesson delivery (Said \& Bin, 2014). These types of Moodle affordances interrelate throughout the teaching and learning process on the platform.

In general, when the perceived Moodle affordance matches with its intended use, learning and operation of the platform becomes easy and hence influence its usage. There have been several studies on Moodle usage and its related issues. For instance, Umek, Aristovnik, Tomaževič, \& Keržič (2015) in their study on Moodle eLearning system and students' performance in Slovenia concluded that implementation of Moodle system increased students' performance. They suggested further research on content quality and technological features of the Moodle platform. Several related studies (Al-Ani, 2013; Costa, Alvelos, \& Teixeira, 2012) have been conducted on Moodle usage among students. Unfortunately, there exist limited studies on the Moodle usage affordance among students in the Senior High Schools in Ghana. This study therefore seeks its justification in filling the knowledge gap by finding out how Moodle affordances influence the use of the Moodle platform among Senior High School students in the Greater Accra region of Ghana. Furthermore, it is envisaged that the findings of the study will create the awareness of the technical and social affordance Moodle present to students and how their challenges are mitigated to motivate them to continue adapting to online learning during this pandemic. Moreover, based on the findings, National Council for Curriculum and Assessment (NaCCA) and the Ghana Education Service (GES) will develop Moodle usage manual to guide student on effective usage of the Moodle to facilitate learning.

\subsection{Research Questions}

In order to ascertain the Moodle affordance among SHS students in the Greater Accra region, the following research questions guided the study.

1) How does technical affordance influence students' usage of the Moodle platform for learning?

2) What are some of the influences that social affordance has on students' usage of the Moodle platform for learning?

\subsection{Delimitation and Limitation of the Study}

Ideally, the researchers' work should have covered all students in the Second Cycle institutions in Ghana but the researcher limited the research to only two Senior High Schools in the Accra Metropolis running the double-tracking system, specifically, Accra Wesley Girls' High School and Accra Girls' High School. The researchers chose these schools for the study because they were easily acces- 
sible to the researchers. On the other hand, administering the questionnaires to the respondents was a difficult task as most of them were not willing to disclose vital information to the researcher. As well, due to the COVID-19 pandemic, the sampling is only a representation of what or who were available in the population rather than of the whole population. As a result, the results or findings of this study cannot be generalized to the whole population. This may be a potential threat to the internal and external validity of the data obtained.

\section{Review of Literature}

\subsection{Theoretical and Empirical Review}

The researchers grouped this section into two main sections. These were the theoretical and the empirical review. The Cognitive Information Process Model of Learning, and The Socio-cultural Model of Learning will serve as the theoretical anchor of this study. Also, review literature on concept of technical and social affordance of Moodle usage whiles the empirical review will highlight some studies conducted by other researchers concerning the technical and social affordance of Moodle platform for learning among students.

\subsubsection{The Cognitive Information Processing Model of Learning}

This model talks about how the mind process information rather than how learning occurs, a theory that Schuell (1986) also contributed to it. Every child is unique and has different style of learning. As a result, Bovy (1981) believes that lessons should be learner-centred by effectively involving the students in the learning process to help each learner achieve their best outcome. A child's previous knowledge will help him understand any new knowledge that will be presented perfectly. Brunning (1983) also suggested that lesson objectives should be stated even before the main lesson begins to trap the attention of the students and to help students know the expected knowledge.

\subsubsection{The Socio-Cultural Model of Learning}

Socio-culture mode of learning comprises both the social and the cultural background of the child. The social aspect describes the home and the environmental background of the child. That is, whether the child is from a poor, middle-class family or well-to-do home or whether the child is exposed to games and other play activities at home or not. Iran-Nejad, McKeachie and Berliner (1990), suggested that student will learn a concept quickly if only it is learner-centred, more beneficial to them and also is geared towards their learning needs. Socio-cultural holds the assertion that students create their own understanding of knowledge based on their interest. As a result, O'loughlin (1992) concluded that students should be actively involved in their own terms, and knowledge should not be culturally biased. The affordance of Moodle usage is from this theory since it brings together students from all spheres of environments and social background and does not promote discrimination among students. 


\subsection{Concept of Technical and Social Affordance of Moodle Usage}

Integration of technology into the curriculum of students has many advantages. For instance, Harvey (2003) revealed that integrating technology into the curriculum of students helps to ensure quick and easy research of information from the internet instead of traveling to a far place just to get information as done in the traditional system. Some researchers contradicted this view by arguing that, although the traditional system is good as it helps students to be able to have a face-to-face interaction with their teachers, it is also costly. With technology usage, such cost is reduced and helped bridge the academic gap thereby improving learning. Most research conducted shows that online learning as a technology-enabled instruction is one of the best ways of learning. Most educators are of the view that online learning contributes greatly to the existence of distance learning. In this regard, Moodle usage affordances in the various institutions help to improve academic performances. This is because it allows students to plan ahead of time and learn accordingly on their own as compared to the traditional or conventional way of learning where the teacher only gives the knowledge during face-to-face interactions. Academic achievements, better or standard of living in our various communities and the sustainability of global competition have been improved with the integration of technology into institutions and day to day activities of schools.

Research shows that technology has helped increased communication. For example, Lloyd and Robertson (2012) and Mestre (2012) came out with the findings that technology has enhanced communication between teachers-teachers, teachers-students and students-students. This has improved the continuous exchange of ideas and information between faculty and students. Social affordance of Moodle usage has also helped in the following ways:

1) To enhance social and collaborative learning: In this case, students acquire knowledge best as they continuously communicate with others on the platform. A learning managing system help users to interact effectively as it offers both synchronous and asynchronous communication tools.

2) Users can communicate through various media: Such of these include; mobile phones, tablets, laptops, etc. In recent years, LMS apps have been installed in cell phones, smartphones, and tablets and can be used for learning. It provides easy way of learning regardless of the location due to mobility capability. Thus, it helps to bridge the learning gap.

3) Mobile affordance of Moodle usage serves as a supplement to computer mediated communication and as such mobile devices have come to support learning. This finding was suggested by many researchers such as Helles (2013) and Hutchby (2001) with Boyd and Ellison (2007) concluding that social affordance is being supported by most mobile devices.

\subsection{Empirical Review}

A study conducted by An, Kim and Kim (2008) explored the affordances of 
e-learning in supporting tertiary teaching and learning. They found that with regards to students' perception of technical aspect of e-learning, students enjoyed learning online as compared to the traditional classroom learning. Regarding students' social aspect of learning, students gave positive responses on collaborating and working together within an online group.

Regarding students' perceived experiences of pedagogical aspect of Moodle usage, they indicated that they acquired the necessary skills in operating on the platform. The researcher concluded that skills acquired on Moodle usage can be used to promote effective teaching and learning. This study was conducted only on tertiary students. Moreover, a study was conducted on Moodle usage and the living curriculum. This paper reviewed how Moodle usage can help in transforming teaching practice. Escobar-Rodriguez and Monge-Lozano (2012) contributed and came out with the findings that Moodle usage offers a wide range of ways in which people can create representations of their knowledge and share them depending on the attitude and technological skills of the teacher. It was therefore concluded that Moodle usage can help transform the behaviors of students towards learning and to help them obtain the necessary learning skills.

\section{Research Methodology}

The researchers' theoretical, philosophical and research paradigm stands for this study emanates from the epistemological viewpoint, the adaptation of the positivism philosophy and the positivist paradigm. A quasi-experimental design was used as the research design. This was to establish the cause-and-effect relationships among the variables. The researcher adopted this research design because this design is most frequently used for non-randomized study. The target population of this research was 1218 students. They comprise all form one and two Green track students in the Accra Wesley Girls' High School and Accra Girls' High School. During the sampling procedure, Yamane (1967) sample size determination formula was used. A margin error of (0.05) is assumed. The sample size was determined as follows:

$$
\begin{aligned}
n & =\frac{N}{1+N(e)^{2}} \\
& =\frac{1218}{1+1200(0.05)^{2}} \\
& =\frac{1218}{4} \\
& =301 \text { Students }
\end{aligned}
$$

where:

$N=$ population size $=1218$ students,

$n=$ sample size,

$e=$ margin of error (0.05).

From the calculation, the sample size of the students is 301, from the total population of 1218, which is the lowest number of responses required from re- 
spondents to maintain a $95 \%$ confident interval. As regards to the sampling procedure, the purposive sampling technique was employed to arrive at 301 students. The main data collection instrument and the data collection were done through the use of a structured questionnaire to address the research questions of the study through the Google form. A five-point Likert scale was designed to elicit responses from the respondents. The questionnaire was pre-tested among some selected senior high school students within the Ashaiman Municipality with sole intention of improving the internal validity of the instruments. The Crombach alpha values for the pre-test were 0.83 and as posited by Fraenkel and Wallen (2000), reliability co-efficient of.70 is seen to be highly reliable for research purpose. Furthermore, STATA 11 was used to interpret the inferential part as significant figures and probability or odd ratios were used in analysing the results. The items for the technical affordance of students were coded as T1, T2, T5, T6, T7, T8 and T9. The items for the social affordance of students were also coded as S1, S2, S3, S5, S7, S8, S10, S11 and S12.

\section{Result and Discussion}

The study obtained data on the demographic characteristics of the respondents. Specifically on their sex, age, usage of online learning platform and preferred learning platforms. These indicators were used to serve as a prerequisite towards Moodle usage.

\section{Sex Characteristics of Student Respondents}

The distribution of the students according to their sex is presented in Figure 1.

As shown in Figure 1, majority of the student respondents being 202 which represents $67 \%$ of the student sample indicated that they were females. Also, 96 out of the 301 students representing 32\% preferred not to say their gender. Only 3 out of the 301 students representing $1 \%$ indicated that they were males. This was a mistake because all the selected SHS schools were girls' schools. Notwithstanding the lapses found, it can be concluded that all the respondents were females.

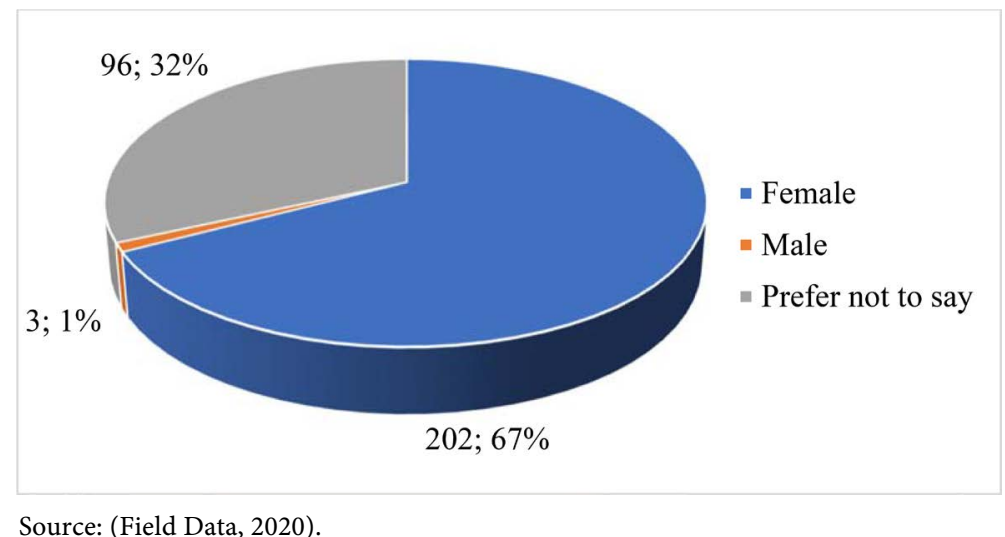

Source: (Field Data, 2020).

Figure 1. Sex characteristics of student respondents. 


\section{Age Characteristics of Student Respondents}

The distribution of the students according to their ages is presented in Figure 2. The result in Figure 2 shows that out of the 301 respondents, students between the ages of $(16-20)$ years represented $39.6 \%$ of the sample while 98 out of the 301 were between the ages of (10 - 15) years representing $32.6 \%$ of the sample.

\section{Students' Self-Reported Usage of Online Learning Platforms}

Figure 3 is a summary of the results of students' self-reported usage of online learning platforms. From the results obtained in Figure 3, 296 out of 301 of the student participants representing $99 \%$ agreed to have used an online learning platform in the past whiles 4 out of 301 students representing 1\% reported that they had not used any online learning platform before.

\section{Respondents Preferred Learning Platforms?}

Figure 4 gives a summary of the type of platform used by students. The results on the type of learning platforms that students have used in the past show that, 249 out of 301 of the sample representing $82.7 \%$ use Moodle learning platform as compared to WhatsApp learning platform with 27 out of 301 representing, 9.0\%

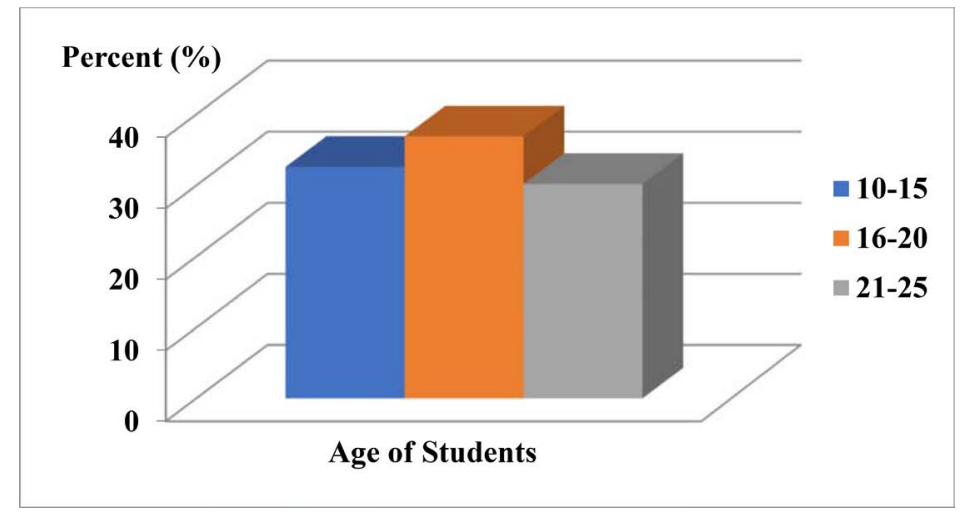

Source: (Field Data, 2020).

Figure 2. Age characteristics of student respondents.

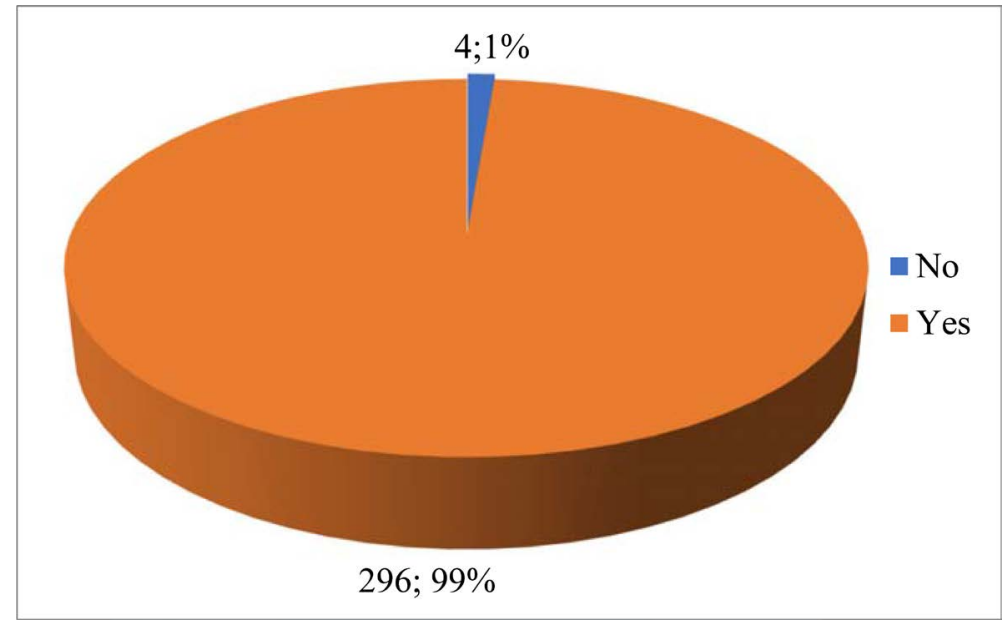

Source: (Field Data, 2020).

Figure 3. Students' self-reported usage of online learning platforms. 
and Edmodo learning platform with 22 out of 301 representing 7.3\%. This finding makes it imperative to investigate the Moodle usage affordance among students as this is their preferred learning platform.

Research Question 1: This research question seeks to find out how technical affordance influences students' usage of the Moodle platform. Logistic regressions analysis of the technical affordance for the students is presented in Table 1.

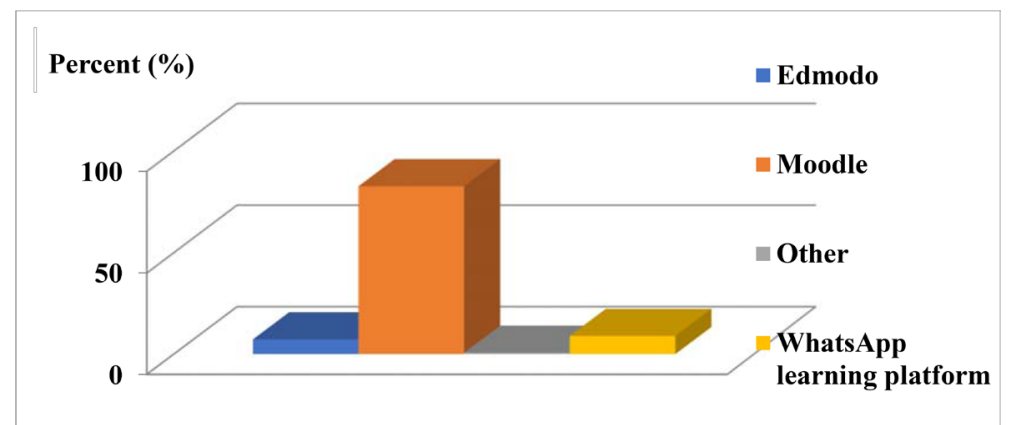

Which of the learning platforms did you use as a student or monitor?

Source: (Field Data, 2020)

Figure 4. Respondents preferred learning platforms?

Table 1. Technical affordances of Moodle usage of students.

\begin{tabular}{|c|c|c|c|c|}
\hline Variable & Odds ratio & Std. Err & $\mathrm{Z}$ & $\mathrm{p}>(Z)$ \\
\hline I was able to upload my profile & 3.959413 & 3.700235 & 1.47 & 0.141 \\
\hline I was able to learn on my own & 16.56872 & 13.1546 & 3.54 & 0.000 \\
\hline $\begin{array}{c}\text { Online learning helped me to access course } \\
\text { learning materials }\end{array}$ & 4.069774 & 3.977109 & 1.44 & 0.151 \\
\hline $\begin{array}{l}\text { I was able to get additional information and } \\
\text { materials for my assignment }\end{array}$ & 2.756786 & 3.053254 & 0.92 & 0.360 \\
\hline $\begin{array}{l}\text { I was able to submit my project work effectively } \\
\text { through the use of the Moodle }\end{array}$ & 13.24459 & 13.37468 & 2.56 & 0.011 \\
\hline I was able to view my grade using the Moodle & 0.065274 & 0.091877 & -1.95 & 0.051 \\
\hline $\begin{array}{l}\text { Moodle usage helped me to get prompt } \\
\text { feedbacks from my colleagues and instructors }\end{array}$ & 2.559447 & 3.062105 & 0.79 & 0.043 \\
\hline Constant & 0.211789 & 0.008837 & 9.24 & 0.000 \\
\hline \multicolumn{5}{|c|}{ Goodness of fit of the model } \\
\hline Number of Observations & & & & 301 \\
\hline $\operatorname{LR~Chi~}^{2}(9)$ & & & & 145.41 \\
\hline Prob $>\mathrm{Chi}^{2}$ & & & & 0.000 \\
\hline Pseudo $\mathrm{R}^{2}$ & & & & 0.6265 \\
\hline Log likelihood & & & & 43.35015 \\
\hline Number of Groups & & & & 3 \\
\hline Hosmer-Lemeshow $\mathrm{ch}^{2}(3)$ & & & & 0.17 \\
\hline
\end{tabular}

Source: (Field data, 2020). 
Results obtained from Table 1 show that, students' ability to submit project work on time through the use of Moodle had effect on the technical affordance of Moodle usage at a statistical significance of $1.1 \%$. This also recorded a higher probability or odd ratio (13.24) of students who were able to submit their project work on time than those who were not able to submit their project work through the Moodle platform on time. Also, on respondents' ability to view their grades using Moodle, it was recorded to have a positive effect on the technical affordance of Moodle usage at a statistic significance of 5\%. This implies that, students who were able to view their grades on the Moodle platform had a higher probability or odd ratio (0.065) of technical affordance than those who were not able to view their grades using Moodle. Furthermore, respondents' capabilities of getting prompt feedbacks from their colleagues and instructors were statistically significant at $4 \%$ showing a positive impact on technical affordance of Moodle usage. This implies that students who were able to receive prompt feedbacks from their colleagues and instructors had a probability or odd ratio (2.559) of technical affordance than those who were not able to receive prompt feedbacks through the use of Moodle. This result confirms earlier studies done in this study by Collis and Moonen (2001), Goodyear et al. (2001), Marra (2002). By reference, their study means that Moodle usage can positively affect students' academics including helping them to submit their project works on time. Moreover, the finding from students' ability to view their grades using Moodle was also supported by a study conducted by Bevan (2001) who mentioned that Moodle has features that help to evaluates students' performances.

Research Question 2: This research question aims at finding out how social affordance influences students' usage of Moodle platform. This question was measured with 9 items and their logistic regression analysis is presented in Table 2.

The result of the logistic regression model in Table 2 reveals the social affordance of Moodle usage of students. From the model, being able to connect with teachers and other students outside the classroom at any time and anywhere affected the social affordance of Moodle usage positively at a statistical significance of $6 \%$. This implies that those who were able to connect with teachers and other students had a higher probability or odd ratio (18.45) of social affordance than those who were not able to connect with teachers and other students regardless of time and location. Analysis on students' ability to share ideas or communicate within the Moodle platform also affected the social affordance of Moodle usage positively at a statistical significance of $4 \%$. A higher probability or odd ratio (8.00) of students who were able to use Moodle to share ideas or communicate effectively was obtained compared to those who were not able to share ideas or communicate within the Moodle platform effectively. Moreover, results obtained from students being able to build their confidence in expressing ideas and thoughts as they worked together on the Moodle platform also affected the social affordance of the Moodle usage positively at a statistical significance of $1 \%$. This therefore implies that, a higher probability or odd ratio (9.23) of such students 
Table 2. Social affordances of students.

\begin{tabular}{|c|c|c|c|c|}
\hline Variable & Odds ratio & Std. Err & $\mathrm{Z}$ & $P>(Z)$ \\
\hline I enjoyed working within an online group & 4.246177 & 4.569594 & 1.34 & 0.179 \\
\hline $\begin{array}{l}\text { I was able to connect with teachers and other } \\
\text { students outside the classroom at any time } \\
\text { and anywhere }\end{array}$ & 18.45727 & 28.65647 & 1.88 & 0.060 \\
\hline $\begin{array}{l}\text { I am able to share ideas or communicate } \\
\text { within an online group }\end{array}$ & 8.004396 & 8.177756 & 2.04 & 0.042 \\
\hline $\begin{array}{l}\text { Working together within an online group } \\
\text { helped my learning }\end{array}$ & 0.697526 & 0.805886 & -0.31 & 0.755 \\
\hline I enjoyed online discussions about my studies & 0.939029 & 1.126221 & -0.05 & 0.958 \\
\hline $\begin{array}{l}\text { Working together within an online group } \\
\text { helped me accomplish higher quality work } \\
\text { than if I was working alone. }\end{array}$ & 0.400622 & 0.437293 & 0.84 & 0.402 \\
\hline $\begin{array}{l}\text { Working together within an online group } \\
\text { helped me to build confidence in expressing } \\
\text { my ideas and thoughts. }\end{array}$ & 9.23035 & 8.367309 & 2.45 & 0.014 \\
\hline $\begin{array}{l}\text { In my online group, we agreed on how to } \\
\text { work together. }\end{array}$ & 0.686161 & 0.750674 & -0.34 & 0.731 \\
\hline $\begin{array}{l}\text { My group members' enthusiasm towards } \\
\text { group activities encouraged me to participate. }\end{array}$ & 1.345726 & 1.503514 & 0.27 & 0.790 \\
\hline Constant & 0.245877 & 0.009641 & -9.45 & 0.000 \\
\hline \multicolumn{5}{|c|}{ Goodness of fit of the model } \\
\hline Number of Observations & & & & 301 \\
\hline $\operatorname{LRChi}^{2}(9)$ & & & & 138.12 \\
\hline Prob $>\mathrm{Chi}^{2}$ & & & & 0.00 \\
\hline Pseudo $\mathrm{R}^{2}$ & & & & 0.5951 \\
\hline Log likelihood & & & & 46.99324 \\
\hline Number of groups & & & & 3 \\
\hline Hosmer-Lemeshow $\mathrm{Chi}^{2}(1)$ & & & & 0.30 \\
\hline
\end{tabular}

Source: (Field data, 2021).

was obtained as compared to those who were not able to involve themselves effectively in any of the discussions on Moodle platform. This finding was backed-up by Alkhalaf et al. (2012), who emphasized that technology helps to bridge the gap between instructors, contents and learners regardless of location and time. Also, Boyd and Ellison (2007) supported this fact by suggesting that social affordance is being supported by most Mobile devices. By reference, it means that with the use of Mobile devices, communication can flow in both directions. (Kulp, 1999 cited in Bonk, 2004) however contradicted this view by stressing that, although Moodle helps to bridge the learning gap, it requires more time and efforts from students to make it effective which serves as a disadvantage to students. 


\section{Conclusion and Recommendation}

Gauging from the findings of the study, it can be concluded that students were able to submit project works on time, viewed their grades and received prompt feedbacks. This study therefore concludes that when students are able to perform these activities with ease, it encourages them to use the Moodle platform well and effectively. Also, students were able to connect with teachers and other students, shared ideas or communicate within the Moodle platform effectively, accomplished higher quality work when working in groups than working alone and built one's confidence in expressing ideas and thoughts as they worked together. As students are purposeful in using technological learning tools and resources, telecommunication agencies can offer some subsidies on the student bundle usage to enable them to explore and discover knowledge for themselves.

In relation to the concept of the technical and social affordance of Moodle usage among students, the researchers make these recommendations to the government, National Council for Curriculum and Assessment (NaCCA), Ghana Education Service and educational policy makers to provide workshops on Moodle usage for students to enable them to acquire the needed technical skills in operating the Moodle platform. Moreover, Moodle operating manuals can be designed for students to serve as a guide to enable students to navigate smoothly when using the Moodle platform.

\section{Acknowledgements}

We wish to acknowledge, with gratitude, our indebtedness to all the reviewers and the editor for their epistemological contribution in making this article a niche in the area of teaching and learning.

\section{Conflicts of Interest}

The authors declare no conflicts of interest regarding the publication of this paper.

\section{References}

Al-Ani, W. T. (2013). Blended Learning Approach Using Moodle and Students' Achievement at Sultan Qaboos University in Oman. Journal of Education and Learning, 2, 96-110. https://doi.org/10.5539/jel.v2n3p96

Alkhalaf, S., Drew, S., Alghamdi, R., \& Alfarraj, O. (2012). E-Learning System on Higher Education Institutions in KSA: Attitudes and Perceptions of Faculty Members. Procedia-Social and Behavioral Sciences, 47, 1199-1205. https://doi.org/10.1016/j.sbspro.2012.06.800

An, H., Kim, S., \& Kim, B. (2008). Teacher Perspectives on Online Collaborative Learning: Factors Perceived as Facilitating and Impeding Successful Online Group Work. Contemporary Issues in Technology and Teacher Education, 8, 65-83.

Bevan, N. (2001). International Standards for HCI and Usability. International Journal of Human-Computer Studies, 55, 533-552. https://doi.org/10.1006/ijhc.2001.0483

Bonk, C. J. (2004). The Perfect E-Storm: Emerging Technologies, Enhanced Pedagogy, 
Enormous Learner Demand, and Erased Budgets. Observatory on Borderless Higher Education.

Bovy, R. C. (1981). Successful Instructional Methods: A Cognitive Information Processing Approach. ECTJ, 29, 203-217. https://doi.org/10.1007/BF02766716

Boyd, D. M., \& Ellison, N. B. (2007). Social Network Sites: Definition, History, and Scholarship. Journal of Computer-Mediated Communication, 13, 210-230. https://doi.org/10.1111/j.1083-6101.2007.00393.x

Brandl, K. (2005). Are you Ready to "Moodle"? Language Learning/Technology, Washington, 9, 16-23.

Brunning, I. L. (1983). An Information Processing Approach to a Theory of Instruction. ECTJ, 31, 81-101. https://doi.org/10.1007/BF02766725

Chindo, S., Bala, U., Tijani, B., Waziri, S., \& Maji, I., K. (2015). Human Capital, Technology, and Economic Growth: Evidence from Nigeria. Sage Open, 5, 97-109. https://doi.org/10.1177/2158244015615166

Collis, B., \& Moonen, J. (2001). Flexible Learning in a Digital World: Experiences and Expectations. Kogan Page.

Costa, C., Alvelos, H., \& Teixeira, L. (2012). The Use of Moodle E-Learning Platform: A Study in a Portuguese University. Procedia Technology, 5, 334-343.

https://doi.org/10.1016/j.protcy.2012.09.037

Crawford, R. (2000). Information Technology in Secondary Schools and Its Impact on Training Information Technology Teachers. Journal of Information Technology for Teacher Education, 9, 183-198. https://doi.org/10.1080/14759390000200082

Escobar-Rodriguez, T., \& Monge-Lozano, P. (2012). The Acceptance of Moodle Technology by Business Administration Students. Computer \& Education, 58, 1085-1093. https://doi.org/10.1016/j.compedu.2011.11.012

Fraenkel, J. R., \& Wallen, N. E. (2000). How to Design and Evaluate Research in Education (704 p). McGraw-Hill Education.

Goodyear, P., Salmon, G., Spector, M. J., Steeples, C., \& Tickner, S. (2001). Competences for Online Teaching: A Special Report. Educational Technology Research and Development, 49, 65-72. https://doi.org/10.1007/BF02504508

Harvey, B. (2003). Investing in Technology: the Impact in Student Learning. ERIC Digest. ERIC Clearinghouse on Information \& Technology. ERIC Document No: ED479843.

Helles, R. (2013). Mobile Communication and Intermediality. Mobile Media \& Communication, 1, 14-19. https://doi.org/10.1177/2050157912459496

Hutchby, I. (2001). Technologies, Texts and Affordances. Sociology, 35, 441456. https://doi.org/10.1177/S0038038501000219

Iran-Nejad, A., McKeachie, W. J., \& Berliner, D. C. (1990). The Multisource Nature of Learning: An Introduction. Review of Educational Research, 60, 509-515. https://doi.org/10.3102/00346543060004509

Jan, H., Amin, S., \& Mattoo, M. (2018). Modular Object-Oriented Dynamic Learning Environment (MOODLE): An Open Learning Platform. Journal of Applied Research in Education, 23, 201-212.

Lloyd, S. A., \& Robertson, C. L. (2012). Screencast Tutorials Enhance Student Learning of Statistics. Teaching of Psychology, 39, 67-71. https://doi.org/10.1177/0098628311430640

Marra, R. M. (2002). The Ideal Online Learning Environment for Supporting Epistemic Development: Putting the Puzzle Together. Quarterly Review of Distance Education, 3, 15-31. 
Mestre, L. S. (2012). Student Preference for Tutorial Design: A Usability Study. Services Review, 40, 258-276. https://doi.org/10.1108/00907321211228318

O’loughlin, M. (1992). Rethinking Science Education: Beyond Piagetian Constructivism toward a Sociocultural Model of Teaching and Learning. Journal of Research in Science Teaching, 29, 791-820. https://doi.org/10.1002/tea.3660290805

Putnam, R. (2006). CEP 805 Teaching and Learning Mathematics with Technology. http://www.projectlearning.org/numeracy/affordances.html

Said, M., \& Bin, M. (2014). Technological Affordances of E-Learning: An Analysis of Students' Perceptions in Tertiary ICT Education. International Journal on Information, 17, 3659-3674.

Schuell, T. J. (1986). Cognitive Conceptions of Learning. Review of Education Research, 56, 411-436. https://doi.org/10.3102/00346543056004411

Treem, J. W., \& Leonardi, P. (2013). Social Media Use in Organizations: Exploring the Affordances of Visibility, Editability, Persistence, and Association. Annals of the International Communication Association, 36, 143-189.

https://doi.org/10.1080/23808985.2013.11679130

Umek, L., Aristovnik, A., Tomaževič, N., \& Keržič, D. (2015). Analysis of Selected Aspects of Students' Performance and Satisfaction in a Moodle-Based E-Learning System Environment. Eurasia Journal of Mathematics, Science and Technology Education, 11, 1495-1505. https://doi.org/10.12973/eurasia.2015.1408a

Yamane, T. (1967). Statistics, an Introductory Analysis (2nd ed.). Harper and Row. 